\title{
EROSION WEAR AND HARDNESS SHORE D OF EPOXY RESIN FILLED WITH PISTACHIO POWDER
}

\author{
Hwazen Salam Fadhil \\ 130143@uotechnology.edu.iq \\ Rusul Salah Hadi \\ University of Technology -Department of Material Engineering
}

\begin{abstract}
In this research, erosion wear rate and hardness shore $\mathrm{D}$ for polymer biocomposite materials were investigated. The present bio-composites made up of differing weight percentage of pistachio shell powder $(0 \%, 5 \%, 7 \%$, and $9 \%)$ with epoxy resin was prepared by hand layout method. The erosion wear rates for bio composites obtained with under constant factors $(10$ hours, $60^{\circ}$ impingement angles, sand silica particles $850 \mu \mathrm{m}$, standoff distance $23 \mathrm{~cm}$, flow rate $45 \mathrm{~L} / \mathrm{min}$, room temperature, nozzle diameter $4 \mathrm{~mm}$ and pump diameter $50 \mathrm{~mm}$ ). Results show that the specimen (epoxy $+9 \%$ pistachio shell powder) has the best erosion wear rate resistance and hardness shore D compared with other specimens, also the specimen reinforced by $9 \%$ pistachio shell have the lower density and highest water absorption percentage and it is found that the improving percentage for the this specimen in hardness is (11.5\%) and in erosion wear rate is $(775 \%)$. The study reveals that the addition of pistachio shell powder to the epoxy reduces its erosion wear rate and semi ductile behavior.
\end{abstract}

Keywords: Erosion Wear, Pistachio shells, Hardness shore D.

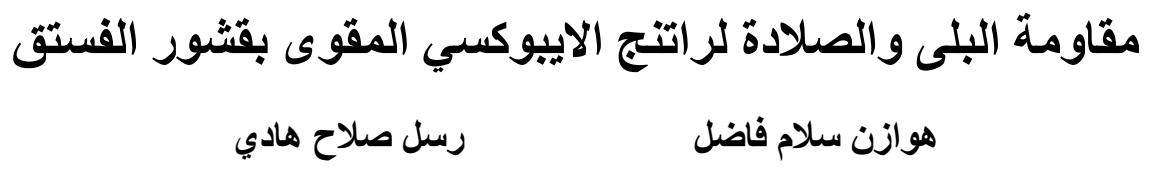

الخلاصة

في هذا البحث تم فحص معدل البلى والصلادة D للمو اد البوليمرية المتر اكبة .تم تحضير العينات المنر اكبة الاحيائية الحالية

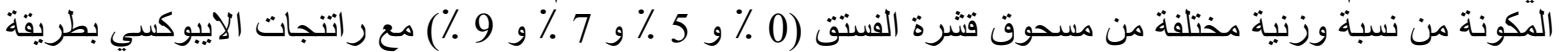

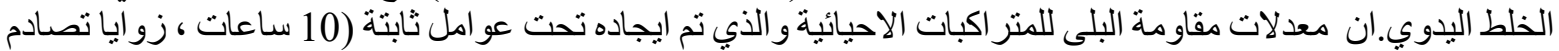

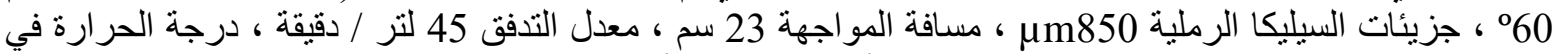

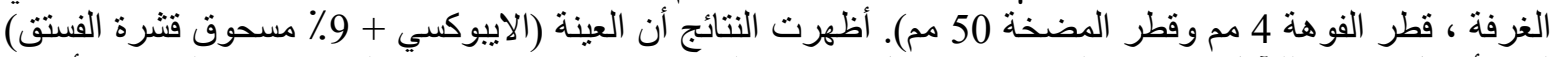

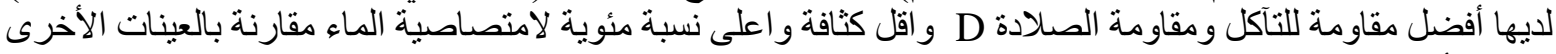
، وتبين أن النسبة المئوية للتحسن لهذه العينة في الصلادة هي (11.5\%) و في معدل مقاومة الفة البلى (775٪).

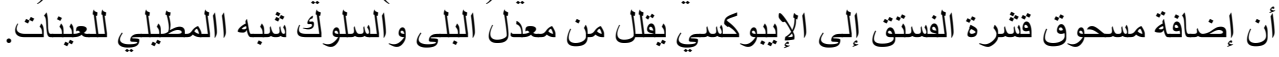




\section{INTRODUCTION}

Over the last years, natural reinforcement received increasing attention as alternative to synthetic reinforcement both from academic world and various industries. There is a variety of different natural materials, which can be used as reinforcements of polymer (i.e. thermosets and thermoplastics) composites. The application of bio composites have a wide range in the industries, especially with natural waste composites, therefore the properties of the composite can be carried out with different techniques (Oleiwi J. K. et. al. 2018). The use of biomaterials such as rice husk, fly ash, wood fiber, carrot fibers act. is gaining popularity in composites due to these materials available and low-cost filler. The epoxy resins are widely used in various applications, making the thermosetting polymers very important. This resin strengthens with different fiber and filler in order to improve mechanical and physical properties, also the chemical properties of this polymer depend on cross-linking agents, initiators, diced, and other additives (A. Basim et. al. 2015) Erosion wear represent degradation of specimen subjected to striking of particles on the surface, where that happened in all applications therefore, there are many of researcher studied the behavior of erosion wear rate of composite reinforced with different filler. (Yaming Z. et.al. 2016) investigated the effect of (16\% with particle size 110 $\mu \mathrm{m})$ and $(84 \%$ with particle size $550 \mu \mathrm{m}) \mathrm{SiC}$ reinforced with epoxy resin on erosion wear and flexural strength. The results show the (epoxy $+84 \% 550 \mu \mathrm{m}$ ) reduce the erosion rate, while the (epoxy $+16 \% 110 \mu \mathrm{m}$ ) has the best flexural strength. (R. Ala et.al 2017) evaluated the erosion wear behavior of polyester resin reinforced with $(2 \%, 4 \%, 6 \%$, and $8 \%$ volume fraction $\mathrm{Al}_{2} \mathrm{O}_{3}$ powder and $4 \%$ carbon fiber). Results show the specimen (UP+4\%C. $\mathrm{F}+8 \% \mathrm{Al}_{2} \mathrm{O}_{3}$ ) has better resistance, erosion wear under factors $\left(425 \mu \mathrm{m}\right.$ particle size of silica sand) and $\left(30^{\circ}\right.$ impingement). (H. Jena et.al. 2018) have studied the erosion wear of two groups polymeric composite: group one constituent from epoxy with (18\%, 28\%, 33\% and $43 \%$ weight fraction) bamboo fiber and second group constituents from epoxy reinforced with $33 \%$ weight fraction bamboo fiber and $(1.5 \%, 3 \%, 4.5 \%$ and $6 \%$ weight fraction cenosphere filler. The specimens reinforced with bamboo fiber and cenosphere filler into epoxy resin give resistance erosion wear better compared with specimens reinforced with bamboo fiber only. (D. Pani and P. Mishra 2018) have investigated the erosion wear and hardness for 6 specimens polymer composite (epoxy $+10 \%$ wt. Luffa fiber), (epoxy $+10 \%$ bagasse fibers), (epoxy $+10 \%$ coir dust), (epoxy $+5 \%$ coir dust $+5 \%$ bagasse fibers), (epoxy+ $5 \%$ Luffa fiber+ $5 \%$ bagasse fibers) and (epoxy $+5 \%$ Luffa fiber+ $5 \%$ coir dust $+5 \%$ bagasse fibers). The results showed that the specimen (epoxy $+5 \%$ Luffa fiber $+5 \%$ coir dust $+5 \%$ bagasse fibers) the best resistance to erosion compared to other specimens. (C.V. Srinivasa and K.N. Bharath 2011) evaluated the effect of areca fiber on properties of the epoxy and found that when the fiber volume fraction increases the mechanical properties (hardness and impact) of the composite increases. (F. R. Al Khalidi and M. A. Rajab 2018 ) studied the properties (hardness and wear resistance) of composite materials reinforced by graphite or silica particles or both, and reinforced with Cuffler fibers and obtained that Hardness values reached their highest value when increasing the volume fracture to $15 \%$ and then decreased to their lowest values at the volumetric fraction (20\%). The aim of this work is utilizing the waste nature material to improve erosion wear and hardness shore D of epoxy resin.

\section{MATERIALS}

Epoxy resin (EUXIT $50 \mathrm{KI}$ ) with density of $1.05 \mathrm{gm} / \mathrm{cm} 3$ was utilized in this study work produced by (Al-Rakaez Building Materials in Amman) made in (Egypt Arabic). Unsalted pistachio shells were obtained from attar in order to avoid hassles of washing. Wash pistachio shell with distilled water to remove any impurities from the outer surface and dry in air for 24 hours. Then grinding the pistachio shell by using electric mill for 2 hours, after which the powder is sieved using an electric sieve to find a particle size of $\leq 50 \mu \mathrm{m}$. The chemical composition of pistachio shell powder after milling is shown in Table(1)using reagents 
Compton secondary molybdenum rand Barkla scatters HOPG ((X-ray Fluorescence).

\section{PREPARATION OF BIOCOMPOSITES}

A glass mold was used for preparing the bio composite specimens. The weight fraction of pistachio shell powder $(5 \%, 7 \%$, and $9 \%)$ was mixed with the epoxy and hardener. After $24 \mathrm{hrs}$ the samples are taken out from the mold and put specimens in the furnace at 55 for 3 hours to remove any stresses and complete bonding between resin and filler (Aseel Basim Abdul Hussein et. al., 2015 \& Oleiwi J. K et. al. 2017). Details composition of specimen composites is presented in Table(2).

\section{MECHANICAL TESTS \\ Erosion wear}

Erosion testing was carried out as per ASTM G 76 (Annual Book of ASTM, 2013). The specimens bio composite were cut with a diameter $(40 \mathrm{~mm})$ and thickness $(5 \mathrm{~mm})$ as shown in figure(1). This figure represented the device that used for erosion test which is manufactured locally. The dimensions of tank were $(40 \mathrm{~cm} * 20 \mathrm{~cm} * 20 \mathrm{~cm})$. Where the sample for from the nozzle by distance $(23 \mathrm{~cm})$ with diameter of pump is $(40 \mathrm{~mm})$ and diameter of nozzle is $(4 \mathrm{~mm})$. This test was done by by using angle between the fluid flow and the horizontal axis of the test specimen $(\alpha)$, at $60^{\circ}$. It is operating flow rate $(45 \mathrm{~L} / \mathrm{min})$. In this test arrangement silica sand of size $(850 \mu \mathrm{m})$ was mixed with water from the air compressor and this jet was targeted onto the test specimens. The conditions under which erosion rate was carried out are listed in Table (3). The specimen weights were noted down before the test as well as after conducting the erosion tests. The test is conducted for 10 hours and weighed the specimens to determine the weight loss. The rate of erosion wear was evaluated by using the following equation (1) (P. Mishra et. al., 2010 \& Reem Alaa Mohammed et.al., 2018).

$$
\text { Erosion wear rate }=\frac{\Delta W c}{\Delta W s}
$$

\section{Hardness shore D}

The Hardness Shore D test is conducted depend on (ASTM D-2240) at room temperature. Specimens cut off into a thickness of $4 \mathrm{~mm}$ and a diameter of $40 \mathrm{~mm}$ (Annual Book of ASTM Standard , 1988).

\section{RESULTES AND DISCUSSION Wear rate of erosion}

The events of wear rate of erosion for the epoxy strengthened with pistachio shell powder are illustrated in figure (3). Impingement particle creates a rise in temperature of the surface which gives the matrix deformation simple due to the great temperature known to occur in solid particle erosion invariably soften the matrix (Tewari U.S. et. al., 2002). On impact, the erodent particle kinetic energy is transferred to the composite body that leads to crater formation and subsequently material loss (Reem Alaa Mohammed et.al., 2018 and Patnaik A. et.al., 2007). The results display, the specimens strengthened with pistachio shell powder give the lower erosion wear rate when they are compared with the specimen epoxy. The reason is that the appearance of pistachio shell powder in the resin matrix assists in absorbing the kinetic energy offered by the impacted erodent particles and therefore making the energy available for the plastic deformation of the matrix to become less (Patnaik A. et.al., 2007). It is obvious from these results the specimen (Epoxy $+9 \%$ pistachio shell) gives better erosion resistance than other specimens, due to lower the mean particle size with a good distribution, bonding, high strength, and stiffness these give an erosion wear rate. The behavior of erosion wear rate of 
composite can be sorted into two groups (ductile and brittle) and depended on the conditions of experiment and the specimen (A. B. Abdul-Hussein, 2015). Also the results show the higher value of erosion wear rate happened at $60^{\circ}$ of impact angle. This represented the behavior of specimen's bio composites to erosion particles. Therefore, the behavior of specimen bio composite can be termed as semi-ductile in nature.

\section{Hardness shore D}

The hardness shore D results of the epoxy reinforced with pistachio shell are shown in figure (4). From results can be noted the increase hardness with added in pistachio shells content, indicating 87 with $9 \mathrm{wt} \%$ pistachio shell due to Increase in pistachio shell content leads to an increase in the hardness this may be due to the fact that the hardness is generally considered to be a property of the surface, also pistachio shell contains elements harder than the pure epoxy that leads to an increase in hardness. The cause of increasing the hardness value of the bio composite materials is the addition of filler lead to increased resistance material for plastic deformation, this result agrees with (R. Alaa Mohammed et.al., 2016 \& Ruaa Haitham AbdelRahim et.al., 2019).

\section{Water absorption}

The water absorption of the epoxy reinforced with pistachio shell are shown in figure(5). The results show that the percentage of water absorption increased with increasing in pistachio shells content and this happened because the matrix materials exhibit low absorption. Thus, the moisture plays a role in deteriorating the interface between the matrix and the reinforced material. The reinforced material may absorb small amounts of water. As a consequence, the adhesion between the matrix material and the reinforced material decreases (I. I. Marhoon, 2016).

\section{Density}

The relationship between the density and content of pistachio powder (\%)shows in figure(6). The density of composite sample decreased with increasing the content of pistachio shell and this is due to This is due to the fact that as the weight fraction of the pistachio shell powder (having lesser density than matrix) increases, the weight fraction of the matrix (having higher density) decreases with decreasing the density of the composites (S. P. Priya, et.al., 2006).

\section{CONCLUSIONS}

The composite specimens were prepared with different weight $(0 \%, 5 \%, 7 \%$, and $9 \%)$ of pistachio shell filled in epoxy resin. From the results the following conclusions are drawn:

1. The presence of $9 \%$ weight fraction pistachio shell reduces the erosion wear rate of biocomposite comparison with other specimens and the percentage in improving at ( $9 \mathrm{wt} \%)$ is $(775 \%)$.

2. The hardness shore D increased with addition of pistachio shell powder and reach maximum value at $9 \%$ weight fraction pistachio shell and the improving percentage is $(11.5 \%)$ compared with other samples.

3. The composites reinforced by $(9 \%)$ of pistachio shell have the lower density and the highest water absorption percentage compared with other specimens. 
Table 1: Chemical composition of pistachio shell powder

\begin{tabular}{|c|c|}
\hline Chemical composition & Wt \% \\
\hline Cellulose & 42 \\
\hline Lignin & 13.5 \\
\hline cellulose lignin & 3.11 \\
\hline $\mathrm{Na}_{2} \mathrm{O}$ & 0.06 \\
\hline $\mathrm{MgO}$ & 0.01 \\
\hline $\mathrm{Cl}$ & 0.03 \\
\hline $\mathrm{K}_{2} \mathrm{O}$ & 0.08 \\
\hline $\mathrm{CaO}$ & 0.07 \\
\hline $\mathrm{Fe}_{2} \mathrm{O}_{3}$ & 1 \\
\hline $\mathrm{Na}$ & 0.04 \\
\hline $\mathrm{Cl}$ & 0.02 \\
\hline $\mathrm{K}$ & 0.06 \\
\hline $\mathrm{Ca}$ & 0.05 \\
\hline $\mathrm{Fe}$ & 0.8 \\
\hline
\end{tabular}

Table 2: Details composition of sample composites

\begin{tabular}{|c|c|}
\hline Specimens & Composition \\
\hline Specimen 1 & $100 \%$ Epoxy resin \\
\hline Specimen 2 & Epoxy + 5\% Pistachio shell \\
\hline Specimen 3 & Epoxy $+7 \%$ Pistachio shell \\
\hline Specimen 4 & Epoxy $+9 \%$ Pistachio shell \\
\hline
\end{tabular}

Table 3 :Factors of erosion wear

\begin{tabular}{|l|c|}
\hline Silica sand particle & $850 \mu \mathrm{m}$ \\
\hline Impingement angles & $60^{\circ}$ \\
\hline Time test & 10 hours \\
\hline Standoff distance & $23 \mathrm{~cm}$ \\
\hline Flow rate & $45 \mathrm{~L} / \mathrm{min}$ \\
\hline Temperature & Room Temperature \\
\hline Nozzle diameter & $4 \mathrm{~mm}$ \\
\hline Pump diameter & $50 \mathrm{~mm}$ \\
\hline
\end{tabular}

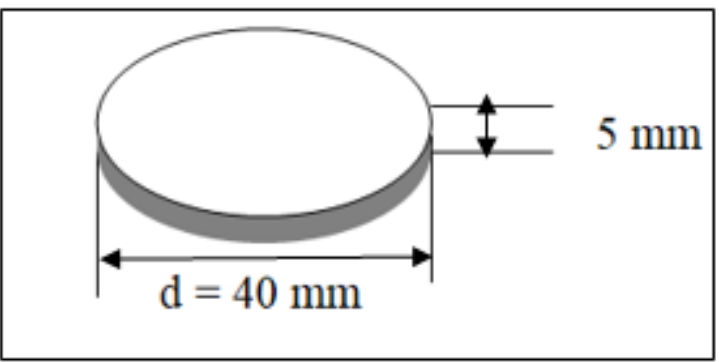

Fig. (1): Specimen dimensions for erosion wear. 


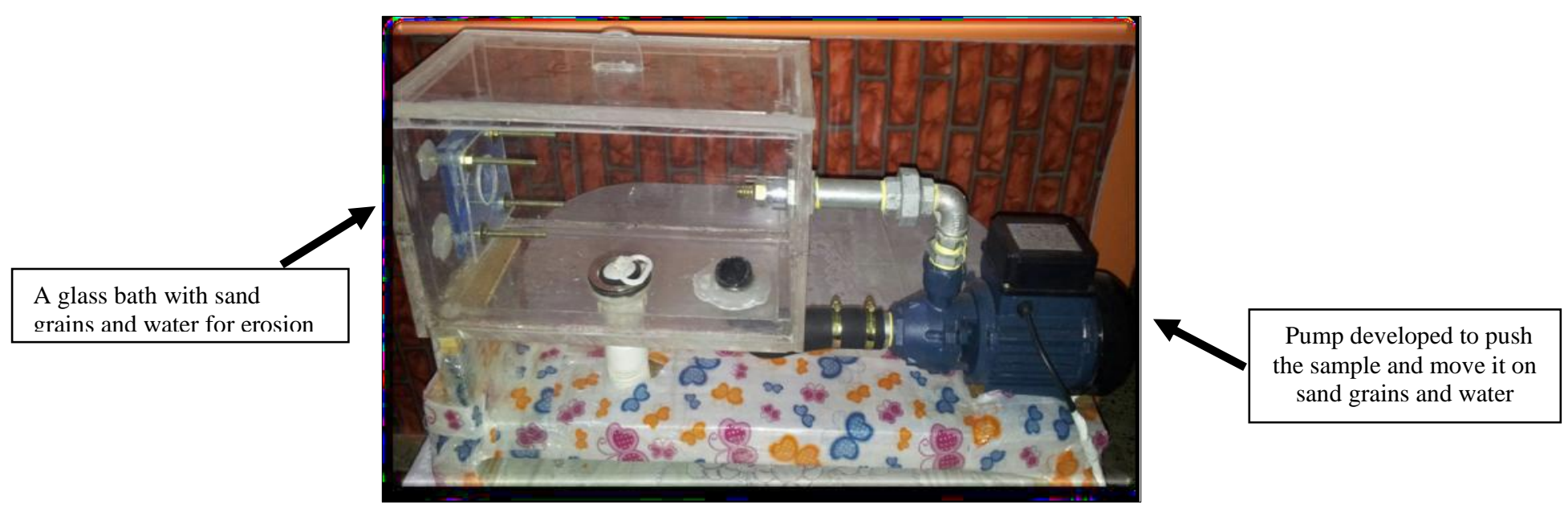

Fig. (2): Erosion wear device.

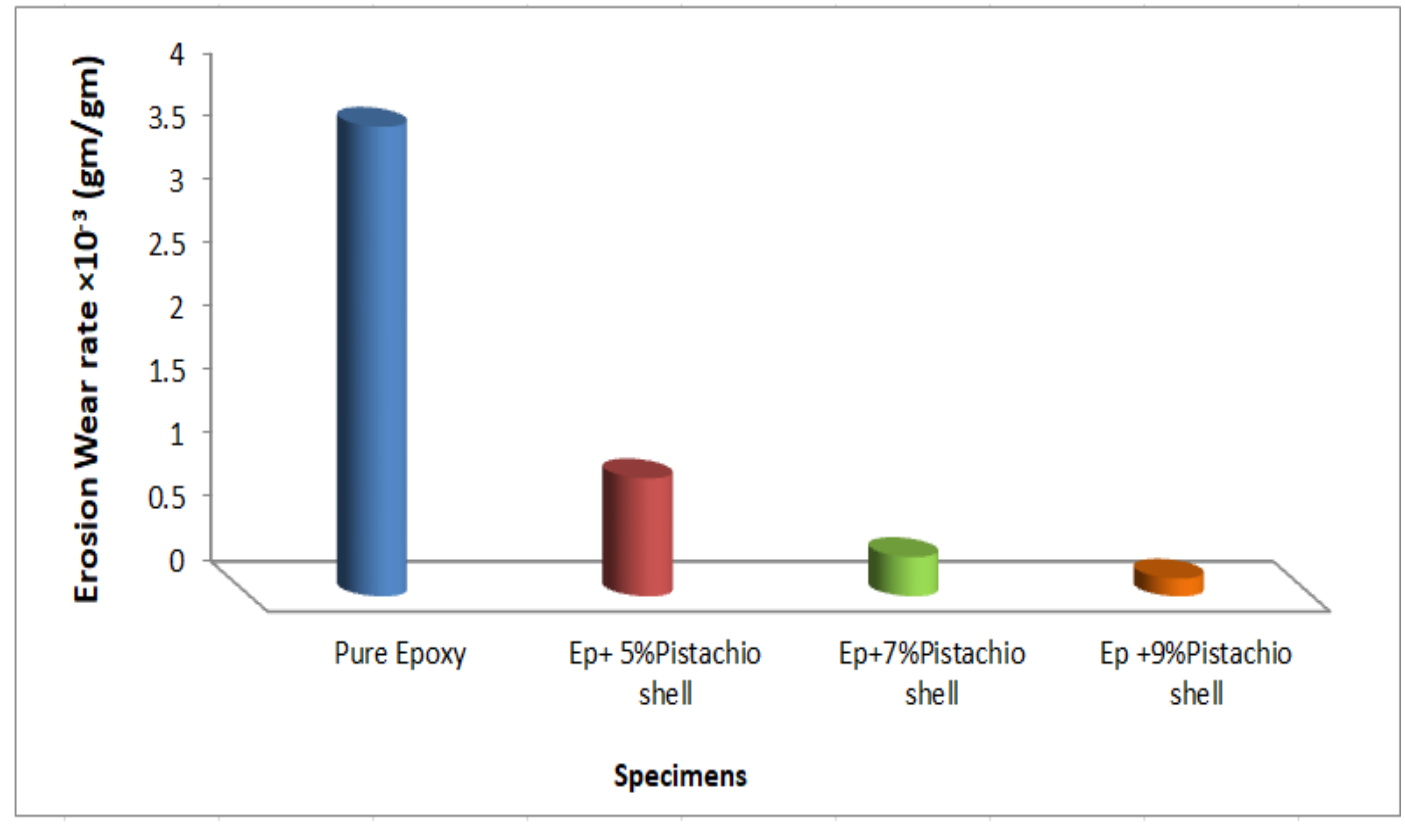

Fig. (3): Erosion wear rate for all specimens.

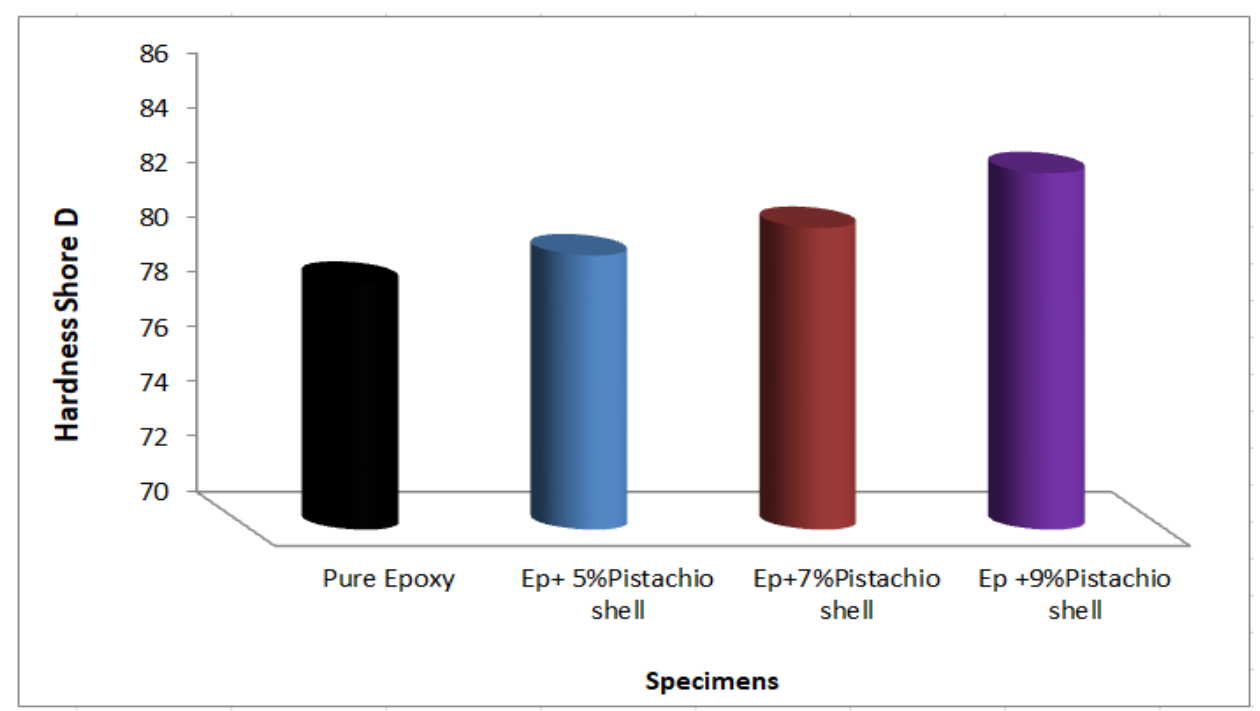

Fig.(4) :Hardness Shore D for all specimens. 


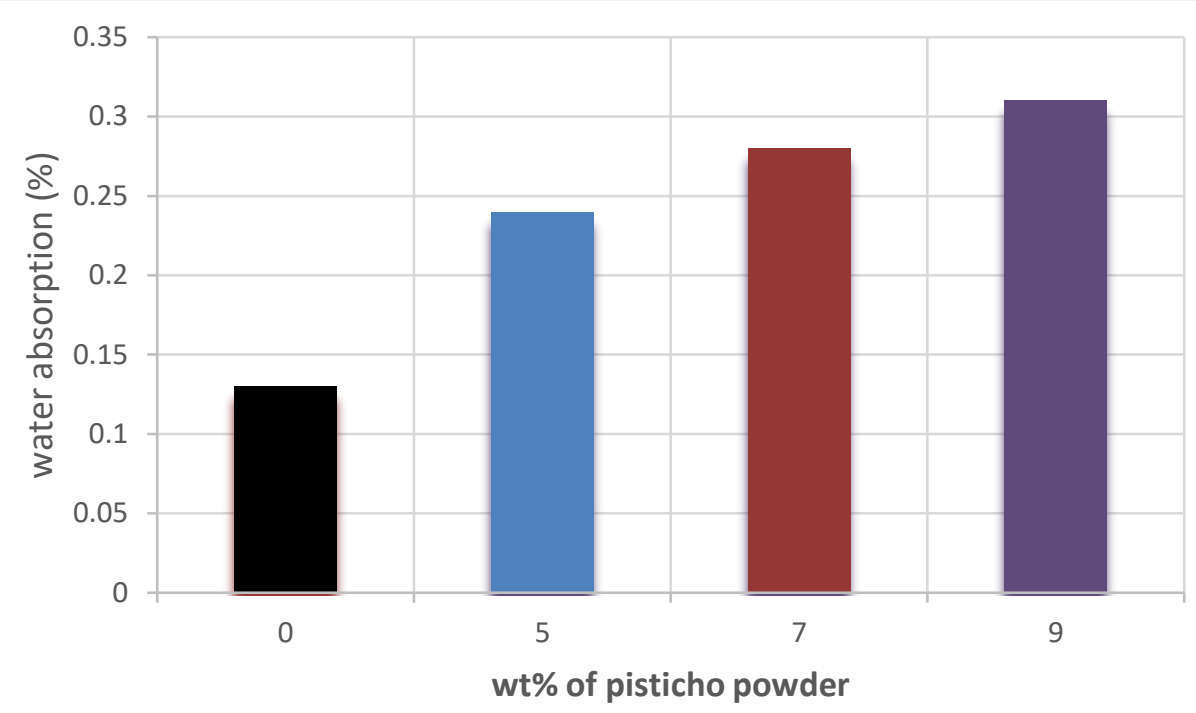

Fig. (5): Water absorption(\%) for all specimens.

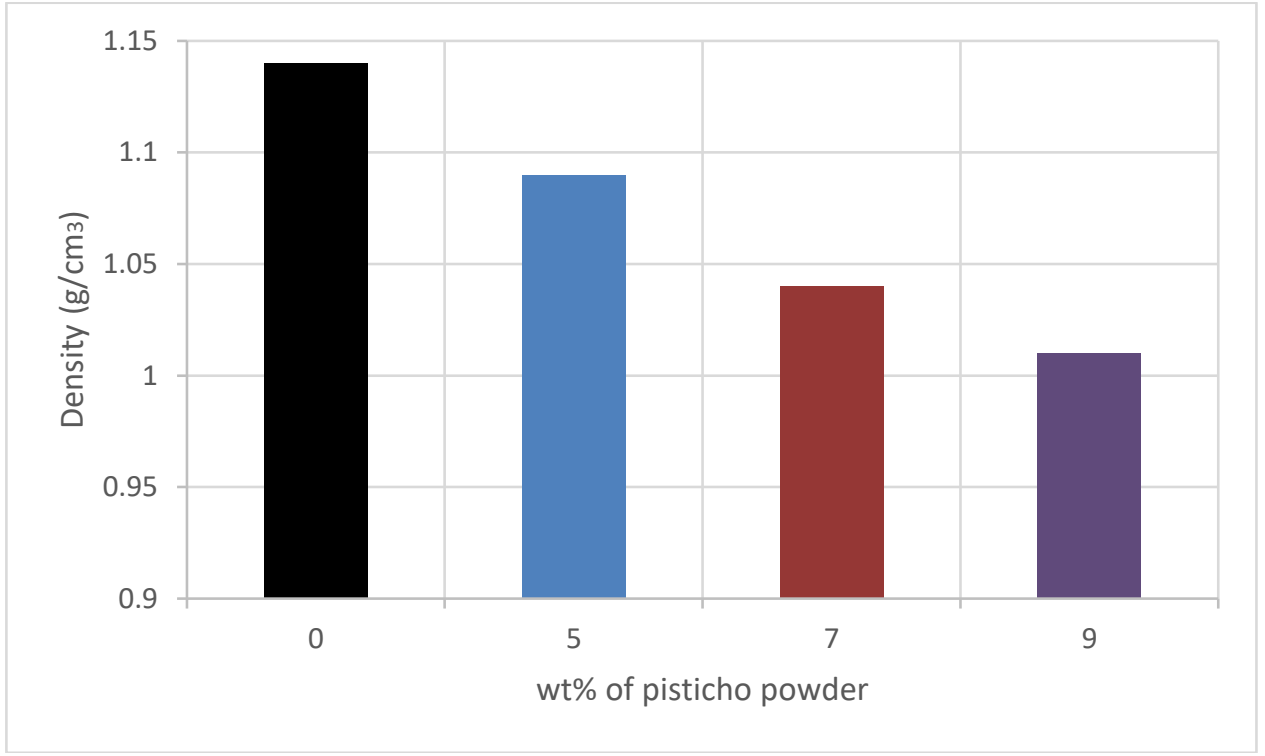

Fig. (6):Density $\left(\mathrm{g} / \mathrm{cm}^{3}\right)$ for all specimens.

\section{REFERENCES}

Oleiwi J. K., Salih S. I., and Hwazen S. Fadhil, "Study Compression and Impact Properties of PMMA Reinforced by Natural Fibers Used in Denture", Engineering and Technology Journal, Vol.36, (Part A), No.6, PP.652-655, (2018).

A. Basim, E. Saadi, Reem Alaa Mohammed, "Influence of Coating with Some Natural Based Materials on the Erosion Wear Behavior of Glass Fiber Reinforced Epoxy Resin ", Al-Khwarizmi Engineering Journal, Vol. 11, No. 2, PP. 20- 30, (2015).

A. B. Abdul-Hussein, E. S. Al-Hassani, Reem Alaa Mohammed, "Erosion Wear Behavior of Industrial Material Reinforced Epoxy Resin Composites and its Coating with Natural Based 
Material ", Eng. \&Tech. Journal, Vol.33, No.4, Part (A), PP.902- 918, (2015).

Y. Zhang, H. Zhang, J. Yangc, and G. Geng, " Erosion Resistance and Interface Properties of Epoxy Composite Filled With Graded Silicon Carbide", Polymers \& Polymer Composites, Vol. 24, No. 2, PP.161-166, (2016).

R. Alaa Mohammed, R. Kamil Majeed, D. Mohammed Gomaa, "Study the Erosion Wear Behavior for Unsaturated Polyester Resin Composites Materials Reinforced by Carbon Fibers with $\mathrm{Al}_{2} \mathrm{O}_{3}$ Powder Using Taguchi Method ", Journal of Engineering and Sustainable Development, Vol. 21, No. 5, PP.213-224, (2017).

H. Jena, A. Kumar Pradhan, M. Kumar Pandit, " Study of Solid Particle Erosion Wear Behavior of Bamboo Fiber Reinforced Polymer Composite with Cenosphere Filler", Advances in Polymer Technology, Vol. 37, No. 3, PP.1-9, (2018), DOI 10.1002/adv.21718.

D. Pani and P. Mishra, "Tribological properties of natural fiber hybrid reinforced polymer composite", Applied Science Innovations Pvt. Ltd., India Carbon - Sci. Tech.,Vol.10, No.4, PP.1726, (2018).

B. V. Srinivasa and K. N. Bharath,"Impact and hardness properties of areca fiber-epoxy reinforced composites", J Mater Environ Sci, Vol.2, No.4, (2011).

A. Khalidi, F. Rashid, and M. A. Rajab, "Hardness and Wear Resistance Of Composite Materials Supported By Graphite And Silica Particles And Reinforced By Cuffler Fiber", American Journal of Engineering Research, Vol.7, No.11, PP.317-322, (2018).

Aseel Basim Abdul Hussein, E. S. Al-Hassani, Reem Alaa Mohammed," Effect of Natural Materials Powders on Mechanical and Physical Properties of Glass Fiber / Epoxy Composite ", Eng. \& Tech. Journal, Vol.33, No.1, Part (A), PP.175- 197, (2015).

Oleiwi J. K., Salih S. I., and Hwazen S. Fadhil, "Effect of Siwak and Bamboo Fibers on Tensile Properties of Self-Cure Acrylic Resin Used for Denture Applications", Journal of Material Sciences \& Engineering, Vol.6, Issue 5, PP.1-6 , (2017), DOI:10.4172/2169-0022.1000370.

Annual Book of ASTM Standard, "Standard Test Methods for conducting erosion tests by solid particle impingement using gas jets," G76-No. 13, (2013).

P. Mishra and S.K. Acharya, "Solid particle erosion of Bagasse fiber reinforced epoxy Composite," International Journal of Physical Sciences, 5, (2010).

Reem A. M.," Study of some Mechanical Properties and Erosive Behavior by Taguchi Method for Hybrid Nano Composites," Engineering and Technology Journal, Vol. 36, Part A, No. 4, pp. 471479, (2018).

Annual Book of ASTM Standard, "Standard Test Method for Plastics Properties- Durometer Hardness D 2240", Vol. 09.01, (1988).

Tewari U.S., Harsha A.P., Häger A.M. \& Friedrich K.," Solid particle erosion of unidirectional carbon fiber reinforced polyetheretherketone composites", Wear Elsevier, Issue 11-12, Vol.252, PP. 992-1000, (2002), doi:10.1016/S0043-1648(02)00063-7.

Patnaik A., Satapathy A. \& Mahapatra S. S., "Implementation of Taguchi method for triboperformance of hybrid composites", Dep. of mechanical Eng. , National Institute of Technology, Rourkela, PP. 779- 788, (2007). 
Reem A. M., " Effect of $\mathrm{Al}_{2} \mathrm{O}_{3}$ Powder on Some Mechanical and Physical Properties for Unsaturated Polyester Resin Hybrid Composites Materials Reinforced by Carbon and Glass Fibers ", Eng. \& Tech. Journal, Vol.34, No.12, Part (A), PP.2371-2379, (2016).

Ruaa Haitham Abdel-Rahim, Reem Alaa Mohammed, "Experimental Investigation of Some Properties of Epoxy reinforced by Egg Shell Particles", International Journal of Mechanical Engineering and Technology, Vol.10, PP.152-163, (2019).

I. I. Marhoon,"Effects of the Addition of Pistachio Shell Particles on the Properties of Polyurethane Matrix Composite," International Journal for research in Applied Science \& Engineering Technology,Vol. 4,PP. 445-49, (2016).

S. P. Priya, H. V. Ramakrishna, and S. K. Rai, "Density, void content, weight reduction, and chemical resistance studies on waste silk fabric reinforced acrylonitrile-butadiene-styrene-toughened epoxy composites", Journal of reinforced plastics and composites, Vol.25, No.4, PP.339-345, (2006). 